педагог технического направления должен сам обладать соответствующими навыками, умениями и способностью к реализации профессиональной деятельности [1].

Подводя итоги, отметим, что в настоящее время можно и нужно повышать качество подготовки будущих преподавателей технического направления. Для этого следует проектировать и использовать современные инновационные педагогические проектные технологии.

Кроме того, мы считаем, что повышение качества подготовки преподавателей технического направления можно обеспечить за счет ее гуманитаризации. Увеличение интереса преподавателей-исследователей к гуманитаризации высшего инженерного образования обусловлено рядом причин. Одна из них состоит в том, что качественная фундаментальная подготовка будущего педагога может быть обеспечена посредством гуманитаризации технического образования в целом. Вторая причина состоит в том, что для решения инженерных задач человеку необходимо иметь определенный культурный уровень, определенный запас знаний, эрудицию. Именно по этой причине исследователи сегодня активно изучают процесс системы высшего инженерного образования. В процессе подготовки педагогов технического направления важно предусмотреть гуманитарные дисциплины (к примеру, культурологию) в образовательных программах инженерных направлений подготовки. Кроме того, следует выявлять возможности технических предметов для гуманитаризации инженерного образования [4].

Подытоживая сказанное, подчеркнем, что деятельность педагогов технического направления в настоящий момент можно рассматривать как систему, объединяющую в себе науку, практическую деятельность и культуру. Качественное техническое образование позволяет науке стать важной производительной силой, а производство, в свою очередь, превращается в объект научного исследования. На сегодняшний день техническое образование вышло за пределы традиционной сферы применения и превратилось в инструмент решения проблем в самых разнообразных областях.

$$
* * *
$$

1. Богоудинова Р.3. Теоретико-методологические обоснования проблемы подготовки конкурентоспособных специалистов // Известия Российской академии образования. - 2017. - № 3 (43). - С. 95-100.

2. Богуславский М.В., Неборский Е.В. Стратегические тенденции развития системы высшего образования в Российской Федерации // Гуманитарные исследования Центральной России. 2017. № 2. С. 7-20.

3. Высшее образование в немецкой и русской традициях: колл.моногр. / М.В. Богуславский, Е.В.Неборский, В.В. Неборская, И.С. Сюткина, Л.А. Юшкова; под общ.ред. М.В. Богуславского. Ижевск: Ин-т компьютерных исследований, 2016. 272 с.

4. Дружилов С.А., Суходольский Г.В. Инженерная психология профессионализма // Вестн. С.-Петербургского ун-та. Сер. 6. 2019. Вып. 3 (№ 22). С. 98-105.

5. Казакова У.А. Развитие профессиональных умений и навыков у преподавателей технологических вузов в ходе переподготовки и повышения квалификации / У.А. Казакова, Ю.М. Кудрявцев // Казанская наука. 2018. - No 3. - C. 11-16.

6. Современное инженерное образование: учеб.пособие / А.И. Боровков [и др.]. СПб.: Изд-во Политехнического ун-та, 2012.

7. Игнатович Е.В., Лопуха А.О. Управление развитием непрерывного образования в вузе: опыт ПетрГУ // Университетское управление: практика и анализ. 2020. № 5 (99). С. 83.

8. Уман А.И. Технологический подход к обучению: учеб.пособие для вузов. М., 2017.

\title{
Галущинская Ю.О. \\ К проблеме реализации педагогической деятельности по организации волонтерского объединения детей и молодежи в организации дополнительного образования
} ФГБОУ ВО «Шадринский государственный педагогический университет» doi: 10.18411/trnio-11-2021-147

(Россия, Шадринск)

\section{Аннотация}

В статье раскрываются теоретические аспекты проблемы реализации педагогической деятельности по организации волонтерского объединения детей и молодежи в организации 
дополнительного образования как системы. Автор определяет основные структурные компоненты данного вида педагогической деятельности, определены условия, способствующие более эффективной ее реализации.

Ключевые слова: волонтерство, волонтерская деятельность, педагогическая деятельность, волонтерское объединение, организация дополнительного образования.

\section{Abstract}

The article reveals the theoretical aspects of the problem of the implementation of pedagogical activities on the organization of a volunteer association of children and youth in the organization of additional education as a system. The author defines the main structural components of this type of pedagogical activity, defines the conditions that contribute to its more effective implementation.

Keywords: volunteering, volunteer activity, pedagogical activity, volunteer association, organization of additional education.

На сегодняшний момент одной из основных целей государственной молодежной политики является наиболее эффективное использование потенциала молодежного волонтерского движения для решения социальных проблем современного российского общества. Волонтерская деятельность является, способом реализации государственной политики в сфере воспитания детей и молодежи, а также средством развития коммуникации государства и молодых граждан общества.

М.Е. Купельдиновой [3] отмечается особая роль волонтерской деятельности как одного из самых эффективных методов формирования и развития жизненных навыков, социализации, самореализации и самоактуализации обучающихся. Следовательно, должным образом организованная волонтерская деятельность в образовательном учреждении способна создать необходимые условия для актуализации личностного потенциала детей и молодежи.

В данной проблеме можно выделить такой еще мало изученный, на наш взгляд, аспект, как исследование педагогической деятельности по организации волонтерской деятельности детей и молодежи в учреждениях и организациях дополнительного образования. Актуальность данной проблемы обосновывается тем, что современным общеобразовательным учреждениям достаточно сложно дать адекватный ответ на социальные, экономические, гражданские общественные вызовы, а также в полной мере реализовать требования, предъявляемые к воспитанию и гражданскому становлению личности. В то время как в системе дополнительного образования накоплен значительный многолетний опыт организации педагогической деятельности по социализации молодого поколения в процессе его участия в различных видах социально-культурной и общественнополезной деятельности, к которым, в том числе, можно отнести волонтерство.

Исходя из этого, мы рассматриваем возможность и значимость исследования проблемы реализации целенаправленной систематической и планомерной педагогической деятельности по организации волонтерского объединения детей и молодежи в организации дополнительного образования (ОДО).

Сама дефиниция «деятельность», являясь сложным феноменом и понятием, используется различными науками; в связи с чем, учитывая важнейшие характеристики данного феномена, необходимо подходить к пониманию деятельности как к сложной категории, представляющую собой активную форму взаимодействия человека с социумом и внешним миром, в процессе которого субъект сознательно и целенаправленно преобразует какие-либо объекты.

В рамках исследуемой нами проблемы субъектом деятельности по организации волонтерских объединений в ОДО является педагог. В научной литературе понятие «педагогическая деятельность» определяется в качестве одного из видов профессиональнотрудовой деятельности; как профессиональная активность педагога, в процессе которой, через разнообразие средств воздействия на обучающихся, решаются образовательные задачи, 
связанные с их личностным, интеллектуальным и деятельностным развитием, воспитанием и обучением [1].

Следовательно, ведущая роль в выборе средств совместной с обучающимися педагогической деятельности принадлежит именно педагогу. Волонтерское движение, на наш взгляд, является одним из таких средств, включающих достаточно широкую палитру способов воздействия на личность обучающихся, с целью развития у них значимых личностных качеств, навыков и умений.

Кроме того, педагогическая деятельность выступает как основа саморазвития и самосовершенствования самого педагога. Приобретая профессиональный опыт, педагог совершенствует умение выбора методов и технологий организации волонтерства, с учетом потребностей и особенностей обучающихся, с целью создания условий для реализации потенциала детей и молодежи в ОДО.

Структурируя педагогическую деятельность как систему, И. Ф. Исаев, Н.Н. Шиянов [5], выделяют три взаимосвязанных компонента: конструктивный, коммуникативный и организаторский. В основе каждого лежат реализуемые педагогом функции или функциональные виды деятельности.

Конструктивный компонент педагогической деятельности по организации волонтерского объединения в ОДО можно представить совокупностью трех видов деятельности: конструктивно-содержательной (планирование и построение педагогического процесса в рамках волонтерского объединения), конструктивно-оперативной (планирование собственных действий и действий обучающихся - волонтеров) и конструктивноматериальной (проектирование предметно-развивающей среды ОДО).

Коммуникативный компонент представлен субъект-субъектным взаимодействием педагога и обучающихся-волонтеров, направленным на развитие и совершенствование, социализацию личности через: усвоение необходимой системы знаний об основах добровольчества и содержании конкретного вида добровольческой деятельности, присвоение ценностей добровольческого движения, овладение разнообразными способами, видами, навыками деятельности.

Организаторский компонент, может быть представлен как единство информирующей, развивающей, воспитывающей, ориентационной и мобилизационной и пр. функций педагогической деятельности, направленной на создание и развитие волонтерского объединения.

Мы согласны с позицией М.С. Кругловой, Л.Е. Сикорской и др. авторов о том, что добровольческая деятельность детей и молодежи может осуществляться с различной степенью контроля, но, как правило, требует компетентного сопровождения, развернутой организационной составляющей. В ОДО необходимо проводить целенаправленную работу не только по привлечению волонтеров из числа обучающихся, но и по их удержанию, мотивированию, гармонично сочетая методы административной и педагогической работы с механизмами волонтерской самодеятельности, самоорганизации и самоуправления [2].

В исследовании Р.К. Сережниковой [4] установлено, что каждый из периодов и этапов педагогической организационной деятельности (определение цели, задачи, структуры и содержания взаимодействия), характеризуется наличием своей системы мотивации (включающей установки, ценностные ориентации, потребности, стремления, желания, побуждения, идеи, идеалы и пр.), которая в определенных ситуациях, связанных с самореализацией личности, способствует возникновению и развитию разнообразных внутренних стимулов деятельности.

Моделируя организацию волонтерской деятельности детей и молодежи, следует также обратиться к общей системе деятельности «субъект-цель-активность-объект». В соответствии с данной системой в роли субъекта волонтерской деятельности в ОДО может выступать как конкретный индивид (обучающийся-волонтер), так и объединение волонтеров (отряд, команда, группа, штаб, центр), осуществляющих просоциальную деятельность. В качестве объектов деятельности выступают отдельные граждане и социальные институты (семья, учреждения системы социальной защиты, образования, здравоохранения) и другие 
объекты. Волонтерская деятельность детей и молодежи может осуществляться в форме: индивидуальной волонтерской деятельности; волонтерской деятельности в составе незарегистрированного объединения или группы; волонтерской деятельности через волонтерскую организацию - объединение.

Педагогическая деятельность по организации волонтерского объединения может обеспечить достижение нужного результата лишь при выполнении ряда условий. К ним мы можем отнести следующие.

1. Обеспечение в процессе педагогической деятельности совместности действий разновозрастных (с учетом возраста) участников на основе сочетания интересов и самоуправления. Деятельность объединения при этом должна иметь общую для всех цель, которая не может быть достигнута каждым членом объединения в одиночку, а только в процессе их взаимодействия.

2. Сосредоточенность педагогической деятельности на личности обучающегося. Поскольку каждый вид деятельности имеет определенное содержание потребностей, мотивов, задач и действий, то деятельность объединения только тогда имеет развивающий эффект, когда мотивы действий, участвующих в ней детей, совпадают с объективными мотивами (значением) общественной деятельности, а сами действия сообразны с объективными способами общественного (социального) действа.

3. Создание возможностей для проявления свободы и равноправия всех участников волонтерского объединения. Известно, что свобода осознается человеком как личное чувство, выражающееся в возможности самостоятельно сделать выбор и отвечать за него. За свободой выбора следует свобода действия, в том числе созидающего, т.е. творчества. Поэтому деятельность объединения должна дать обучающемуся право осуществить самостоятельный выбор (содержания деятельности, ее участников, времени, форм и способов осуществления, способов взаимодействия в процессе нее), принять решение и выполнить его.

4. Деятельность должна носить вариативный характер, чтобы отвечать запросам обучающихся и влиять на их развитие, что предполагает дифференциацию ее содержания, форм и способов (методов, средств) и ориентированность процесса на многомерность состояний личности (здоровье, настроение, привязанности, личные проблемы...). То есть, она должна быть построена таким образом, чтобы каждый был востребован в силу индивидуально-личностного смысла ее содержания и форм реализации.

5. Самодостаточность содержания и способов его реализации. Как известно, деятельность тогда становится фактором развития, когда не только соответствует жизненным проблемам, интересам обучающихся ОДО, входящих в волонтерское объединение, и создаваемые в нем организационные структуры, но и удовлетворяет их, создавая условия для творчества и созидательной активности.

Итак, содействуя личностному самоопределению и социализации участника волонтерской деятельности необходимо ориентироваться на его личные качества, способности, возможности и потенциальные ресурсы (в выборе роли, степени участия, видов и содержания деятельности). Именно поэтому необходима педагогическая деятельность по сопровождению внутренней работы личности обучающихся над самоопределением, мотивацией, формированием ценностно-смысловых ориентаций, развития социальнозначимых качеств личности, рефлексии, самоактуализации.

$$
* * *
$$

1. Верхотурова, Ю.А. Педагогическая деятельность как психолого-педагогический феномен Ю.А. Верхотурова, Ю.Н. Галагузова // Педагогическое образование в России. - 2019. - № 3. - С.62-67. 
2. Круглова, М.С. Совершенствование управления деятельностью волонтерских организаций на примере высших учебных заведений : дис. ... канд. экон. наук : 08.00.05 / М.С. Круглова. - Сочи, 2017. - 171 с.

3. Кульпединова, М.Е. Воспитательные возможности детских общественных объединений / М.Е. Кульпединова // Воспитание детей - инвестиции в будущее! : сб. статей Всероссийского форума (г. Владимир, 8-10 сентября 2016 г.) / отв. редактор. А.А. Сергеенко. - Москва : ИИУ МГОУ, 2016. - С. 182-188.

4. Сережникова, Р.К. Ценностно-синергетический подход к организации педагогического процесса в высшей школе / Р.К. Сапожникова // Высшее образование в России. - 2012. - № 3. - С. 77-81.

5. Сластенин, В.А. Педагогика / В.А. Сластенин, И.Ф. Исаев, Н.Н. Шиянов. - Москва : Академия, $2004 .-576$ с.

\section{Гусева А.X. \\ О модификации методических подходов в преподавании профессиональных дисциплин лингвистам: концепция и практика}

ФГБОУ ВО «Российский государственный гуманитарный университет»

(Россия, Москва)

doi: 10.18411/trnio-11-2021-148

\section{Аннотация}

Публикация посвящена содержательному обновлению дисциплин профессионального цикла в системе ВО. В работе представлена комбинаторная методика преподавания образовательного модуля «Технологии перевода» студентам-лингвистам, описана методическая концепция, приведены примеры из практики ведения занятий, а также проанализированы основные инструменты программных продуктов, изучаемых студентами в процессе освоения рассматриваемой дисциплины.

Ключевые слова: технологии перевода, профессиональные компетенции, методика преподавания, комбинаторная методика, программное обеспечение, цифровые инструменты, модуль системы перевода.

\section{Abstract}

The publication is devoted to the substantive renewal of the disciplines of the professional cycle in the HE system. The paper presents a combinatorial methodology for teaching the educational module «Translation Technologies» to linguistic students, describes the methodological concept, gives examples from the practice of conducting classes, and analyzes the main tools of software products studied by students in the process of mastering the discipline in question.

Keywords: translation technologies, professional competencies, teaching methods, combinatorial methods, software, digital tools, translation system module.

В связи с введением режима самоизоляции представители многих профессий были вынуждены освоить коммуникационные платформы и интернет-сервисы, позволяющие работать в режиме онлайн, проводить совещания, редактировать документы и обмениваться ими по электронной почте, чатам, коммуникационным платформам, корпоративной сети. Отметим, что профессия переводчика и ранее подразумевала удаленную работу с использованием различных цифровых инструментов, что явилось несомненным стимулом для разработчиков новых версий ПО.

На современном этапе развития специализированного программного обеспечения переводчика, а также в связи с широким распространением коммуникационных платформ, работодатели предъявляют к выпускникам вузов повышенные требования к владению информационно-коммуникационными технологиями в процессе перевода. Именно данным фактом и объясняется введение в обязательную программу обучения образовательного модуля «Технологии перевода» для студентов 5 курса Института лингвистики ФГБОУ ВО РГГУ.

Образовательный модуль «Технологии перевода» позволяет определить степень применения специализированного программного обеспечения переводчика в 